\title{
Sistem Deteksi Fibrilasi Atrium menggunakan Fitur RR Elektokardiogram dengan Jaringan Syaraf Tiruan
}

\author{
Eka Anzihory, ${ }^{*}$ Nuryani, ${ }^{\dagger}$ dan Darmanto \\ Jurusan Fisika, Fakultas Matematika dan Ilmu Pengetahuan Alam, \\ Universitas Sebelas Maret (UNS), Jl. Ir. Sutami 36A Kentingan, Surakarta 57126
}

Intisari

Penelitian untuk deteksi gangguan jantung fibrilasi atrium (AF) pada elektrokardiogram (EKG) dengan metode Jaringan Syaraf Tiruan (JST) menggunakan fitur statistik RR telah berhasil dilaksanakan. Pada penelitian ini digunakan tiga metode JST yaitu Learning Vector Quantization (LVQ), Radial Basis Functon (RBF), dan Multilayer Perception-Backporpagation (MLP-BP) untuk menentukan JST yang terbaik dalam mendeteksi AF. Hasil terbaik ditunjukkan pada JST RBF dengan masukan 7 macam fitur dari statistik deskriptif RR pada panjang segmen EKG 15 denyut dengan kinerja berupa sensitivitas, spesifisitas, serta akurasi sebesar 99,97\%, $99,84 \%$ dan $99,89 \%$.

\begin{abstract}
Research for Atrial Fibrillation detection at electrocardiogram (ECG) using Artificial Neural Network (ANN) with RR statistic features has been successfully implemented. This study was conducted by varying RBF NN, MLP-BP NN and LVQ NN to determine the best of ANN in detecting AF. The best results were found when seven features from RR statistic features at length 15 beats of ECG segment by using RBF NN. The best performance were $99,97 \%, 99,84 \%$ and $99,89 \%$ in terms of sensitivity, specificity and accuracy, respectively.
\end{abstract}

KATA KUNCI: atrial fibrillation, RR statistic features, artificial neural network

\section{PENDAHULUAN}

Fibrilasi atrium (AF) merupakan gangguan irama pada jantung yang paling sering ditemui dan merupakan faktor risiko yang signifikan bagi penyakit kardiovaskular. AF dialami oleh $1-2 \%$ populasi dan diprediksi akan meningkat dalam 50 tahun kedepan [1]. Di Amerika Serikat diperkirakan 2,3 juta penduduk menderita AF dengan $>10 \%$ penderitanya berusia di atas 65 tahun dan diperkirakan jumlahnya terus bertambah menjadi 4,78 juta pada tahun 2035 [1]

Permasalahan utama untuk mengenali AF sejak dini adalah gangguan ritme yang terjadi sering bersifat asimtomatik sehingga sepertiga pasien AF menjadi kurang waspada akan penyakit ini. Padahal jika AF mampu di deteksi secara dini, deteksi dini penyakit tersebut dapat membuat pasien diterapi seawal mungkin sehingga prognosis penyakit tersebut menjadi lebih baik [2].

Otomotisasi diagnosis AF dilakukan oleh Mateo dan Rieta pada tahun 2013 [3] dimana sinyal EKG yang merekam aktivitas kelistrikan jantung dengan ciri-ciri khas dalam amplitudo, morfologi, durasi dari gelombang, segmen dan interval terekam dalam suatu tampilan $[4,5]$. Sinyal EKG kemudian diolah lalu dijadikan sebuah informasi masukan bagi

\footnotetext{
*E-MAIL: Anzihoryeka@gmail.com

†E-MAIL: nuryani@mipa.uns.ac.id
}

jaringan syaraf tiruan (JST). JST merupakan sistem pemroses informasi yang mirip dengan jaringan syaraf biologis dan digunakan dalam klasifikasi data atau dalam pengenalan pola melalui tahap pelatihan dan tahap pengujian [6].

Pada penelitan ini fitur statistik RR pada panjang segmen EKG 15 denyut digunakan sebagai masukan JST dalam menentukan ritme AF dan normal. Kemudian tiga metode JST yaitu Learning Vector Quantization(LVQ), Radial Basis Function (RBF), dan Multilayer Perception-Backpropagation (MLP-BP) dikaji untuk menentukan mana JST terbaik pada rancangan sistem ini yang mampu mendeteksi AF.

\section{METODE PENELITIAN}

Rancangan utama sistem deteksi AF menggunakan metode JST ini ditunjukkan pada Gambar 1. Data yang digunakan sebagai bahan penelitian diambil dari basis data Massachusetts Institute of Technology Beth Israel Hospital (MIT-BIH). Pada penelitian ini digunakan data dari 17 pasien.

Fitur-fitur yang digunakan dalam penelitian adalah fitur yang termasuk kedalam statistik deskriptif RR, yaitu fitur ratarata $\mathrm{RR}\left(\mathrm{RR}_{\text {ave }}\right)$, standar deviasi $\mathrm{RR}\left(\mathrm{RR}_{\text {std }}\right)$, maksimum $\mathrm{RR}\left(\mathrm{RR}_{\max }\right)$, minimum $\mathrm{RR}\left(\mathrm{RR}_{\text {min }}\right)$, median $\mathrm{RR}\left(\mathrm{RR}_{\text {med }}\right)$, modus $\mathrm{RR}\left(\mathrm{RR}_{\text {mod }}\right)$, dan jangkauan $\mathrm{RR}\left(\mathrm{RR}_{j n}\right)$. Fiturstatistik RR tersebut disertai dengan panjang segmen 15 denyut, karena menurut penelitian Tatento [7] ritme EKG AF dan normal dapat diambil dari panjang segmen EKG tertentu untuk 


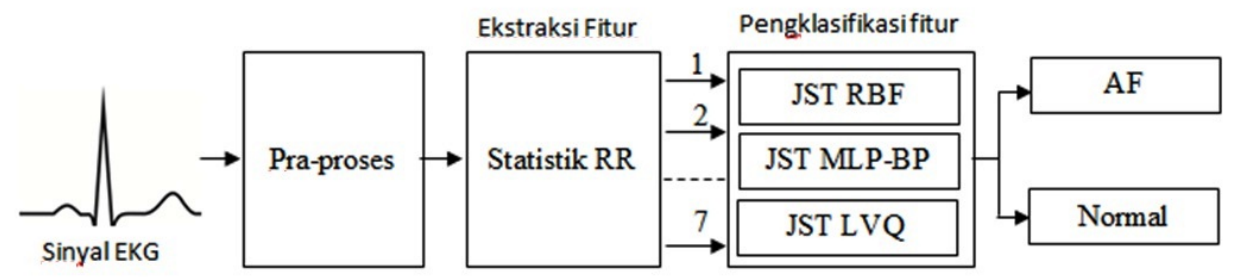

Gambar 1: Rancangan utama sistem dekteksi AF.

TABEL I: Hasil ekstraksi dari seluruh pasien.

\begin{tabular}{lll}
\hline \hline Fitur & AF & Normal \\
\hline $\mathrm{RR}_{\text {ave }}(\mathrm{ms})$ & 171,86 & 207,09 \\
$\mathrm{RR}_{\text {std }}(\mathrm{ms})$ & 6,13 & 7,05 \\
$\mathrm{RR}_{\text {max }}(\mathrm{ms})$ & 699 & 699 \\
$\mathrm{RR}_{\text {min }}(\mathrm{ms})$ & 101 & 101 \\
$\mathrm{RR}_{\text {med }}(\mathrm{ms})$ & 160 & 205 \\
$\mathrm{RR}_{\text {mod }}(\mathrm{ms})$ & 101 & 189 \\
$\mathrm{RR}_{\text {jn }}(\mathrm{ms})$ & 593 & 593 \\
\hline \hline
\end{tabular}

menghasilkan fitur pembeda. Fitur-fitur tersebut kemudian dimasukan ke dalam sistem JST untuk selanjutnya diklasifikasikan menjadi AF atau normal.

Sistem JST terdiri dari dua tahapan, yaitu tahap pelatihan dan tahap pengujian. Data yang digunakan pada tahap pelatihan ini sebanyak $10 \%$ dari total keseluruhan data. Setelah tahap pelatihan selesai, selanjutnya menuju tahap pengujian. Pada tahap ini digunakan data sebanyak $90 \%$ dari total data keseluruhan. Tiga metode JST yaitu LVQ, RBF, dan MLP-BP dikaji untuk menentukan JST yang terbaik dalam mendeteksi AF.

\section{HASIL DAN PEMBAHASAN}

Penelitian terkait deteksi AF dengan metode JST menggunakan fitur-fitur statistik RR dalam panjang segmen EKG 15 denyut telah dilakukan. Penelitian dilakukan dengan mengimplementasikan metode tersebut pada perangkat lunak Mat$l a b$. Total keseluruhan data yang digunakan yaitu sebanyak 830.143 denyut, terdiri 355.649 denyut AF, dan 474.494 denyut normal. Jumlah ini berasal dari total data 17 pasien yang digunakan.

Hasil ekstraksi fitur ditunjukan sebagai mana Tabel I. Pada Tabel I dapat dilihat bahwa proses ekstraksi menghasilkan beberapa fitur yang mampu membedakan AF dan normal, dan juga beberapa fitur lainnya yang belum mampu membedakan antara AF dan normal. Fitur terbaik yang mampu membedakan antara AF dan normal diantaranya adalah fitur RRave, sedangkan fitur RRmax dan RRjn termasuk kedalam fitur yang belum mampu membedakan antara AF dan normal.

Pada bagian ekstraksi fitur, rata-rata interval RR didapati sebagai fitur yang paling signifikan dalam membedakan AF dan normal. Interval RR dalam ritme AF yang lebih pendek ini menyatakan bahwa denyut jantung pada ritme AF terjadi lebih cepat dibanding dengan denyut jantung normal. Hal ini terjadi karena sinyal-sinyal listrik di atrium tidak terorganisir, sehingga menyebabkan kontraksi yang sangat cepat dan tidak teratur (fibrilasi). Sebagai akibatnya, darah terkumpul di atrium dan tidak benar-benar dipompa ke ventrikel. Ini ditandai dengan detak jantung yang sangat cepat sehingga gelombang $\mathrm{P}$ di dalam EKG tidak dapat dilihat [8]. Ketidakmunculan gelombang $\mathrm{P}$ mengakibatkan jarak antara puncak $\mathrm{R}$ di dalam ritme $\mathrm{AF}$ dengan puncak $\mathrm{R}$ sebelumnya menjadi lebih sempit.

Hasil ekstraksi fitur kemudian digunakan sebagai masukan untuk ketiga JST, dengan tahapan pelatihan dan pengujian dilakukan pada masing-masing JST tersebut. Hasil dari tahap pelatihan ditunjukkan dalam bentuk grafik performa JST serta sensitivitas, spesifisitas dan akurasi. Grafik performa JST dari tiga macam JST yang digunakan dapat dilihat pada Gambar 2. Dari gambar tersebut terlihat bahwa JST RBF memiliki performa paling baik dibanding dengan JST MLP-BP maupun LVQ. Hal ini terbukti dengan penurunan nilai mean square error (mse) yang signifikan pada epoch ke-1 sampai dengan nilai epoch sekitar 50, dan pada epoch selanjutnya memiliki nilai mse cenderung konstan dengan nilai sekitar 0,003 . Mse merupakan rata-rata selisih kuadrat antara hasil perhitungan JST dengan keluaran yang diharapkan. Sedangkan epoch adalah jumlah perulangan pembelajaran atau biasa disebut dengan iterasi. Pada JST MLP-BP dan LVQ, besarnya mse pada epoch 50 berturut-turut memiliki nilai sekitar 0,03 dan 0,59 .

Setelah menentukan bahwa JST RBF menghasilkan performa terbaik dengan aristektur yang ditunjukan seperti pada Gambar 3, penentuan kinerja kemudian dilakukan setelah melewati pelatihan dan pengujian dari JST tersebut. Tiga parameter digunakan dalam penentuan kinerja, yaitu sensitivitas, spesifisitas serta akurasi. Sensitivitas merupakan jumlah denyut AF yang terdeteksi AF dibanding total denyut AF. Spesifisitas adalah jumlah jumlah denyut normal yang terdeteksi normal dibanding total denyut normal. Sedangkan akurasi merupakan perbandingan jumlah denyut AF dan normal yang terdeteksi benar dengan jumlah total denyut AF dan normal. Ketiga parameter ini ditunjukkan dalam bentuk prosentase.

Perhitungan sensitivitas, spesifisitas serta akurasi berturut- 


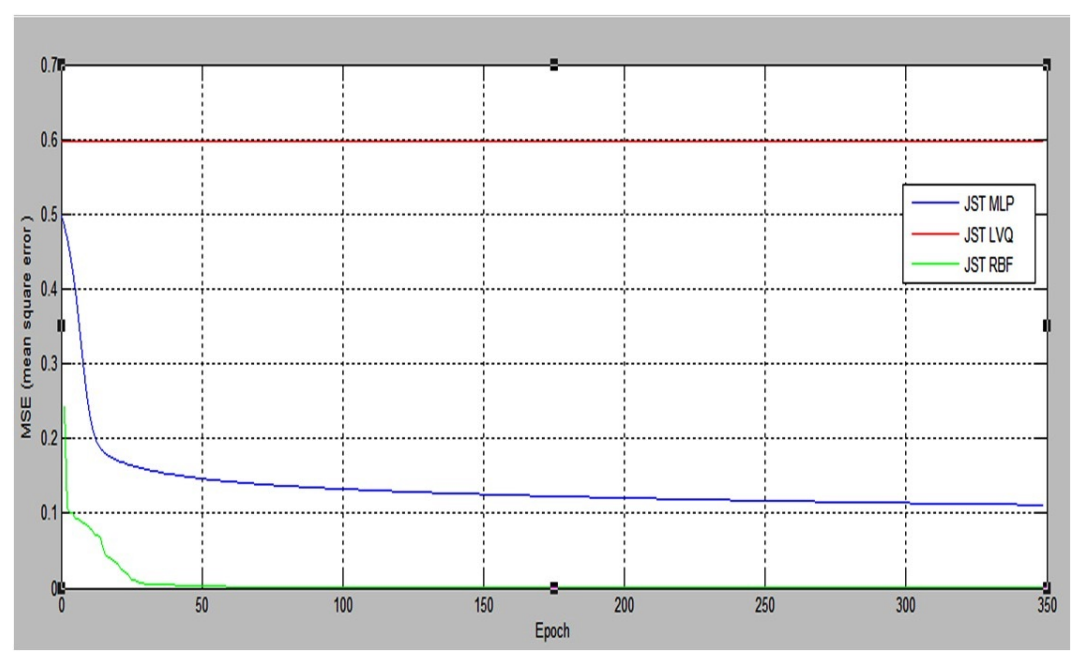

Gambar 2: Performa JST RBF, MLP-BP dan LVQ.

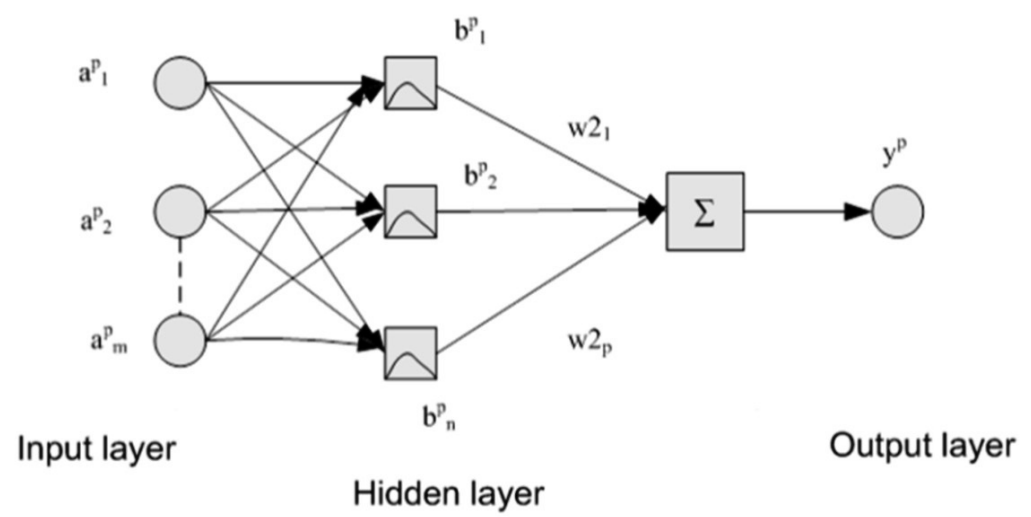

Gambar 3: Arsitektur JST RBF [9].

turut ditunjukkan pada persamaan berikut:

$$
\begin{aligned}
\text { Sensitivitas }(\%) & =\frac{T P}{T P+F N} \times 100 \\
\text { Spesifisitas }(\%) & =\frac{T N}{T N+F P} \times 100 \\
\text { Akurasi }(\%) & =\frac{T P+T N}{T P+T N+F P+F N} \times 100
\end{aligned}
$$

dengan TP (True Positive) adalah jumlah denyut AF yang terdeteksi dengan benar, FP (False Positive) adalah jumlah denyut AF yang terdeteksi salah, FN (False Negative) adalah jumlah denyut normal yang terdeteksi salah, serta TN (True Negative) adalah jumlah denyut normal yang terdeteksi benar. Melalui persamaan tersebut kemudian dihasilkan nilai sensitivitas, spesifisitas dan akurasi darimasing-masing JST yang dikaji, sebagaimana ditunjukan pada Tabel II.

Hasil terbaik ditunjukkan dengan kinerja berupa sensitivitas, spesifisitas dan akurasi pada pengujian JST RBF yang secara berturut-turut bernilai $99,97 \%, 99,84 \%$ dan $99,89 \%$.
TABEL II: Sensitivitas, spesifisitas dan akurasi pengujian

\begin{tabular}{|c|c|c|c|}
\hline JST & Sensitivitas & Spesifisitas & Akurasi \\
\hline LVQ & $100 \%$ & $0 \%$ & $40,70 \%$ \\
\hline MLP-BP & $96,90 \%$ & $95,39 \%$ & $96,03 \%$ \\
\hline $\mathrm{RBF}$ & $99,97 \%$ & $99,84 \%$ & $99,89 \%$ \\
\hline
\end{tabular}
darimasing-masing JST untuk tujuh fitur masukan statistik RR pada panjang segmen EKG 15 denyut.

\section{SIMPULAN}

Pada penelitian ini telah dibuat rancangan sistem deteksi AF dengan fitur statistik RR pada panjang segmen EKG 15 denyut. Rancangan sistem deteksi tersebut diperoleh dengan metode JST yang diimplementasikan pada perangkat lunak MATLAB. Penelitian dilakukan dengan disertai variasi metode jaringan syaraf tiruan, yaitu Learning Vector Quantization (LVQ), Radial Basis Functon (RBF), dan Multilayer Perception (MLP) yang kemudian dikaji untuk menentukan JST yang terbaik dalam mendeteksi AF. Dari hasil pengujian 
menggunakan data klinik EKG, hasil terbaik diperoleh dari JST RBF yang menggunakan ketujuh fitur dalam fitur statistik RR pada panjang segmen 15 denyut. Hasil terbaik tersebut ditunjukkan dengan kinerja berupa sensitifitas, spesifisitas dan akurasi pada pengujian JST yang secara berturut-turut bernilai $99,97 \%, 99,84 \%$ dan $99,89 \%$.
[1] I.Yansen, and Y. Yuniadi, Tata Laksana Fibrilasi Atrium: Kontrol Irama atau Laju Jantung, Cermin Dunia Kedokteran, 40, 171-175(2013).

[2] A.J. Camm, et al., Eur Heart J., 31, 2369-2429 (2010).

[3] J. Mateo, J.J. Rieta, Computers in Biology and Madicine, 43(2), 154-163 (2013).

[4] M.S. Thaler, The Only EKG Book You'll Ever Need (Fifth Edition, Pennsylvania: Lippincott Williams \& Wilkins, 2007).

[5] V.C.R. Seisdedos, et al., Biomedical Engineering Online, 10(1), 1-11 (2011).
[6] A.M. Vanage, R.H. Khade, and D.B. Shinde, IJCEM International Journal of Computational Engineering \& Manegement, 15(4), 75-80 (2012).

[7] K. Tatento, L. Glass, Medical \& Biological Engineering \& Computing, 39, 664-671 (2001).

[8] I.A. Philip, P.T.W. Jeremy, At Glance Sistem Kardiovaskular (Jakarta: Erlangga, 2010).

[9] O.A. Oulodolapo, A.A. Jimoh, P.A. Kholopane, Journal of Energy in Southern Africa, 23(3), 40-46 (2012). 